\title{
Chapter 5: Attitudes to Multiculturalism and Cultural Diversity
}

\author{
Andrew Markus
}

It is a complex matter to unravel attitudes to multiculturalism and cultural diversity. Taking specific poll findings at face value can lead to misrepresentation, evidenced in the contending claims made from time to time concerning the level of support for multiculturalism.

Representatives of ethnic communities, not surprisingly, will seek to stress poll findings that indicate high levels of support for cultural diversity. Thus in February 2008, Sam Afra, Chairman of the Ethnic Communities' Council of Victoria, issued a press release to rebut findings of a local study released in February 2008 which indicated little support for government funding for cultural maintenance:

Recent VicHealth research with a broader representative sample found that $89 \%$ of Victorians think cultural diversity is a good thing. In that research only a minority of Victorians oppose cultural diversity ... Victoria has a proud history of settling people from different backgrounds successfully and harmoniously. Our cultural diversity enriches us socially, culturally and economically ${ }^{1}$.

The lumping together of separate issues escaped notice.

In a February 2009 statement Hieu Van Le, Chairman of the South Australian Multicultural and Ethnic Affairs Commission, released an almost identical finding of a South Australian survey:

$87.7 \%$ of South Australians believe cultural diversity is a positive influence in our community. Nearly half of those surveyed had more than five friends or colleagues with different cultural backgrounds. More than $40 \%$ believe diversity has produced a greater range of skills and knowledge in South Australia. These results demonstrate something that we have known for a long time - South Australia is one of the most harmonious societies on Earth. However, this level of appreciation of

\footnotetext{
1 Afra, Sam (2008). Letter published in The Herald Sun, 7 February 2008, Ethnic Communities Council of Victoria, http://eccv.org.au/community/letters/letter-published-in-the-herald-sun-7-february-2008/, accessed 25 January 2010.
} 
the benefits of cultural diversity is not something we can be complacent about. We have worked long and hard to create and maintain our enviable high level of understanding and appreciation of the benefits and richness that cultural diversity brings ${ }^{2}$.

As in the press release from Sam Afra, a range of issues are mixed. If it is the case, for example, that 'diversity has produced a greater range of skills and knowledge in South Australia', then why 'more than $40 \%$ ', not a majority, agree with this proposition? How does this finding relate to the view of 88 per cent of respondents that 'cultural diversity is a positive influence in our community'?

On the other the hand, there has been no shortage of commentators to present the view that only a minority of Australians support multiculturalism. The journalist Alan Wood, writing in the The Australian in September 2007, based his analysis on the findings of the 1988 FitzGerald Committee inquiry into immigration which 'found a key problem in maintaining support for immigration was a profound distrust by Australians of the policy of multiculturalism'. Wood referred to the 1994 argument of the historian John Hirst that the problem with multiculturalism was that it reduced mainstream Australians to an 'ethnic group', labeled 'Anglo-Celt', demeaned its heritage and denied its right to primacy ${ }^{3}$. Other political scientists and historians, notably Professor Geoffrey Blainey, commenting on the policies of the Keating and Hawke governments, had developed a critique of multiculturalism in similar terms ${ }^{4}$. Such critique reached its fullest development with the rise of Pauline Hanson's One Nation movement in the years 1996-98.

Of the critics of multiculturalism the most detailed analysis of public opinion surveys is to be found in the work of Katharine Betts, particularly her 1988 study Ideology and Immigration, republished in 1999 in an expanded and revised edition as The Great Divide. Betts argued that multiculturalism developed in government policy in the 1970s on the promise that cultural diversity would enrich society. Yet 'the majority of old Australians showed little enthusiasm for this development and, as their understanding of it increased, their limited enthusiasm diminished ${ }^{\prime 5}$. There was a clear split in support for cultural diversity between the university educated - labeled

\footnotetext{
2 Hieu Van Le (2009). 'Multicultural South Australia', Multicultural SA Newsletter, February 2009, http:// www.multicultural.sa.gov.au/documents/MulticulturalSANewsletterFeb2009.pdf, accessed 8 April 2009.

3 Wood, Alan (2007). 'Multiculturalism becomes poison for social capital', The Australian, 26 September 2007.

4 Markus, Andrew (2001). Race: John Howard and the remaking of Australia, Allen and Unwin, Sydney.

5 Betts, Katharine (1999). The Great Divide: Immigration politics in Australia, Duffy and Snellgrove, Sydney: $124-5$.
} 
'the new class'- and the rest of the population. In her analysis the lack of support for multiculturalism contributed to the 'growing majority distaste for immigration'.

Following Hirst, Betts distinguished two meanings of multiculturalism, the first of which received widespread support while the latter did not: (a) the idea that we should be tolerant ('soft multiculturalism'); (b) the idea that we should welcome cultural diversity, including support the provision of government funding and other forms of assistance to immigrant groups to facilitate cultural maintenance ('hard multiculturalism' $)^{6}$.

Betts used findings from a 1994 poll to support her argument concerning the division in Australian society. The poll found that nearly three fifths of university-educated respondents favoured 'hard multiculturalism' compared to a quarter of non-university educated people ${ }^{7}$. Betts concluded that 'Australian surveys and opinion polls on immigration since the 1960s document increasing opposition among the majority of respondents and a growing split between the opinion of university-educated people and that of the majority's.

Recent polls provide further support for Betts' argument concerning division of opinion and bring into question the sweeping assertions of the advocates of multiculturalism. They also, however, provide evidence of change, which, contrary to predictions in the 1980s and 1990s, has seen a lessening of division on settlement and immigration issues and can be expected to contribute to further lessening. For the present, 'hard multiculturalism' is an issue that sharply differentiates the attitudes of immigrants of non-English speaking background (NESB) and those of English-speaking background (ESB), notably long-time Australians. The political significance of this division has, however, been neutered by the Howard and Rudd/Gillard governments in their avoidance of policies of 'hard multiculturalism'. The recognition that government provisions of funds to immigrant groups for ethno-specific ends is an issue easily politicised is reflected in the cautious approach of the Rudd/Gillard Labor government (compared to the earlier policies of Hawke and Keating Labor). Caution seems to be based on the recognition that multiculturalism is difficult to sell in the electorate, although strongly favoured within many immigrant communities. 
Multiculturalism and Integration

\section{Analysis of public opinion}

The following discussion isolates for analysis public opinion on four separate issues:

1. Cultural and ethnic diversity.

2. Multiculturalism considered in general or abstract terms.

3. 'Hard' multiculturalism.

4. Assimilation of immigrants.

Before proceeding, however, it is important to establish that in Australia the value of immigration is widely endorsed in times of economic prosperity. Crossnational surveys locate Australia in the category of countries with a positive view of immigration. The 2003 International Social Survey Program (ISSP) provides the basis for cross-national analysis; in the following, comparison is made between attitudes in Australia, Canada, Great Britain and the states of Germany which, prior to reunification, comprised West Germany ${ }^{9}$.

In response to the question of whether the number of immigrants should be increased, remain the same or be reduced, a minority of Australians (39 per cent) and of Canadians (34 per cent) favoured reduction, compared with a majority in Great Britain (77 per cent) and Germany (70 per cent).

In response to the proposition that immigrants are good for a country's economy, 71 per cent of Australians and 61per cent of Canadians were in agreement, compared with 22 per cent of Britons and 29 per cent of Germans.

When presented with the proposition that immigrants improve the country by 'bringing in new ideas and cultures', 75 per cent of Australians and 68 per cent of Canadians were in agreement, compared with 34 per cent of Britons and 57 per cent of Germans.

\section{Cultural and ethnic diversity}

Australian surveys indicate wide endorsement of the value of immigration for bringing new ideas and cultural diversity. Five surveys between 1995 and 2003 tested responses to the general proposition that 'immigrants make Australia open to new ideas and cultures' and found consistently strong endorsement.

9 International Social Survey Programme (2003). National Identity II, SPSS data file, http://www.issp.org/ data.shtml, accessed 8 April 2009. 
These surveys elicited positive responses in the range 70-80 per cent. In 2007, in response to the proposition that 'accepting immigrants from many different countries makes Australia stronger', 69 per cent were in agreement.

A series of surveys undertaken by Professor Kevin Dunn and Associate Professor Jim Forrest, between 2001 and 2008, found agreement above 84 per cent with the general proposition that it is a good thing for society to be made up of different cultures' ${ }^{10}$.

A 2008 South Australian government survey found that 88 per cent of respondents believe cultural diversity is a positive influence in the community. The survey with the largest number of respondents, Community Indicators Victoria conducted in 2007 and with over 24,000 respondents, produced an almost identical level of agreement with the proposition that it is a good thing for a society to be made up of people from different cultures' ${ }^{11}$.

These surveys indicate that when the issue of cultural diversity is raised in the abstract and most general terms, the level of agreement reaches the range 70-90 per cent. But, indicative of the lack of surety and strength of opinion, when the issue was raised in negative terms in 1988, a large majority of respondents (69 per cent) agreed with the proposition that 'having lots of cultural groups in Australia causes lots of problems.'

\section{Multiculturalism considered in general or abstract terms}

A second type of question relates to multiculturalism (as distinct from cultural diversity) raised in general terms. This issue elicits similar high levels of endorsement to questions relating to cultural diversity raised in general terms.

When in 1988-89 respondents were presented with the statement that 'multiculturalism is necessary if people from different cultures are to live in harmony', 77 per cent were in agreement. In 1997, asked whether 'multiculturalism has been good or bad for Australia?, 78 per cent agreed that it had been good. In 2005 the same question found 70 per cent in agreement. A second survey in 2005 asked respondents if they supported or opposed 'a policy of multiculturalism in Australia' -80 per cent were in support ${ }^{12}$.

10 Dunn, K, Forrest, J, Ip, D, Babacan, H, Paradies, Y and Pedersen, A (2008). 'Challenging Racism: The anti-racism project', conference paper, 4Rs conference, 30 September 2008, http://www.uws.edu.au/_data/ assets/pdf_file/0020/42185/State_level_comparison_for_4Rs_conference.pdf, accessed 8 April 2009.

11 Vic Health (2007). More Than Tolerance: Embracing diversity for health. A summary report, Victorian Health Promotion Foundation, Carlton South: 35.

12 For details of specific polls, see Goot, Murray (1999). 'Migrant numbers, Asian immigration and multiculturalism: trends in the polls, 1943-1998', National Multicultural Advisory Council, Australian 
But when there is suggestion of government action which might encourage separatism, support declines. In 1996, in response to the statement that 'successive Australian governments have adopted a policy of multiculturalism, [a policy that] involves encouraging migrants to become Australians without having to give up their own culture', 61 per cent of respondents were in agreement. In 2002 a poll asked respondents 'how much should migrants be encouraged to keep their cultural identity; 52 per cent were in support of substantial cultural maintenance, 48 per cent were equivocal or against.

\section{‘Hard' multiculturalism}

A third type of question elicits views concerning government support for cultural maintenance; in response to such a question support shrinks to a small minority. Four polls in 1995, 2003, 2007 and 2009 asked for response to the statement that 'ethnic minorities should be given government assistance to preserve their customs and traditions'; the first two polls found a small minority of 16 per cent in support, the third poll 32 per cent and the fourth 33 per cent in support.

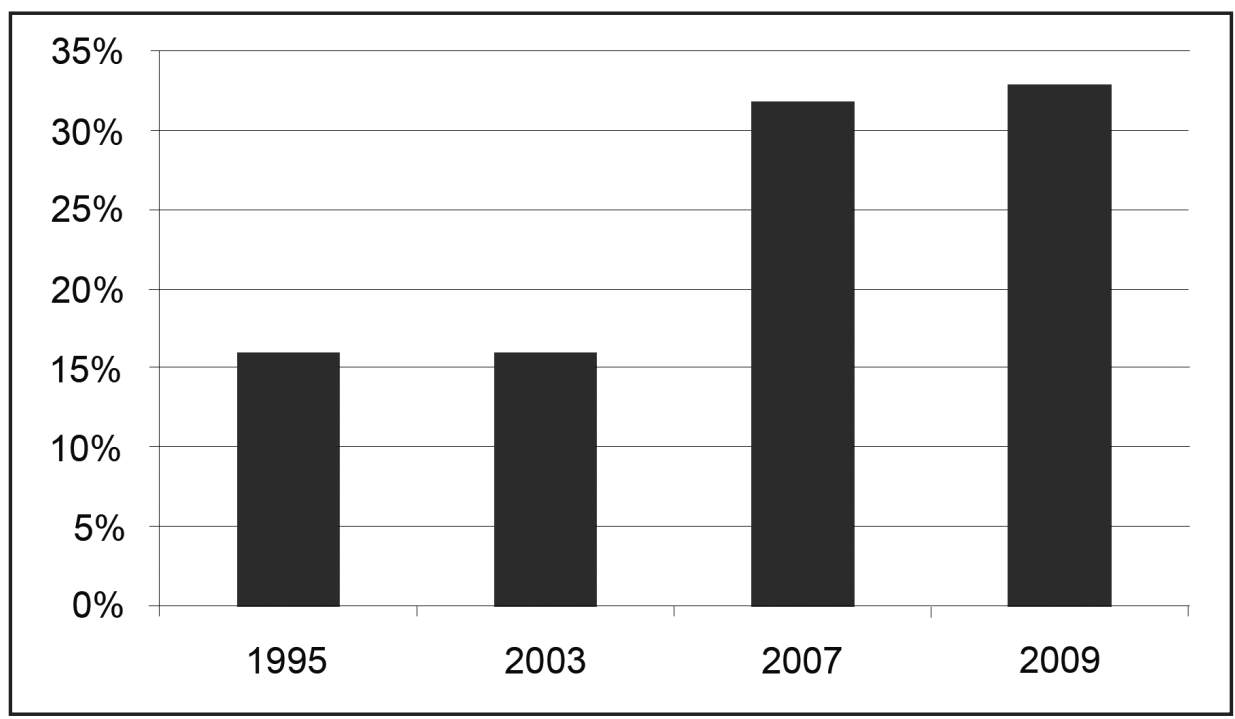

Figure 1 Government assistance to ethnic minorities to preserve their customs and traditions, 1995, 2003, 2007, 2009

Source: Mapping Social Cohesion (2009)

Multiculturalism for a New Century, Statistical Appendix part 2, http://www.immi.gov.au/media/publications/ multicultural/nmac/statistics.pdf, accessed 8 April 2009; Markus, Andrew, Jupp, James and McDonald, Peter (2009). Australia's Immigration Revolution, Allen and Unwin, Sydney: Ch. 7. 
The logic of questions which raise the issue of government funding to minorities means that there will necessarily be limited support, and the response to such question needs to be carefully interpreted. The negative finding may relate more to the dynamics of majority opinion, which will not support funding and the conferring of other benefits on 'others'; thus it may be that the negative finding relates less to the specific issues raised and more to the nature of such questions. But additional evidence is provided by a fourth type of question relating to the idea that immigrants should assimilate to the dominant culture.

\section{Assimilation of immigrants}

When in 1988 respondents were asked whether 'people who come to Australia should change their behaviour to be more like other Australians', a clear majority, 66 per cent, were in agreement. When two polls conducted in 1992 and 1993 posed the general proposition that 'Immigrants to this country should be prepared to adopt the way of life of this country' there was a very high level of agreement, 87 per cent in the first poll and 86 per cent in the second; 13 per cent and 14 per cent respectively were in disagreement.

A poll in 1994 made possible a clearer testing of opinion, providing respondents not with a statement but with options. Respondents were asked which of two statements came closer to their view: 'Migrants should learn to live and behave like the majority of Australians' or 'We should welcome and respect migrants who have different ways of living and behaving'. Sixty-one per cent of respondents favoured the first proposition, that migrants should live like the majority, 35 per cent were in agreement with the view that there should be a welcome and respect extended to those who have different ways.

The 2003 International Social Science Program survey posed two similarly differentiated options:

Some people say that it is better for a country if different racial or ethnic groups maintain their distinct customs and traditions. Others say it is better if these groups adapt and blend into the larger society. Which of these views comes closest to your own ? $^{13}$

This question, although framed in general terms, yielded an even sharper differentiation of opinion, with 18 per cent in agreement with maintenance of traditions and 82 per cent in support of adaptation. This question was posed most recently in 2009, in a different survey context; 15 per cent of respondents

13 ISSP (2003). Op cit. 
agreed with maintenance of traditions, 59 per cent considered that it was better if there was adaptation, while a further 26 per cent volunteered that they agreed with both propositions ${ }^{14}$.

A series of polls conducted in 1993, 1998 and 2006, in a Melbourne suburb adjacent to a region of high immigrant concentration, considered the attitudes of respondents who were born in Australia, with one or both parents born in Australia ${ }^{15}$. The respondents were almost exclusively of Anglo-Celtic background. This group was presented with three options for settlement policy. Immigrants should be 'Encouraged to fit into the community as soon as possible', 'Left to fit in at their own pace', or 'Assisted by government funds to maintain their own culture during their first years in Australia'. A narrow time period, 'their first years in Australia', was thus specified. Across the three polls, the consistent finding was that almost no respondents ( 2 per cent, 1 per cent, 3 per cent) supported the government funding option. In contrast, 79 per cent, 80 per cent and 83 per cent supported encouragement to fit into the community as soon as possible. The maximum support reached in the three polls for the laissez-faire solution - 'left to fit in as soon as possible'- was 13 per cent.

Three national polls conducted in 1994, 1996 and 1997 elicited a response to the forthright statement that 'Immigrants to Australia should adopt our way of life even if they have to put their own traditions and culture behind them'. The results were consistent across the three polls, with 59-62 per cent in agreement.

There is thus majority support for the view that immigrants should assimilate to Australian norms of behaviour at the cost of their own customs - depending on the wording of the question, around 60-80 per cent are in agreement, with a few poll findings above 85 per cent.

\section{Variables}

In considering public opinion, it is important to consider the distribution of attitudes across sub-groups in the population. This close analysis provides indication of possible direction of change and may be of importance for the targeting of information strategies and other government programs. Sub-groups

14 Markus, Andrew (2009). Mapping Social Cohesion 2009, Institute for the Study of Global Movements, Monash University, http://www.globalmovements.monash.edu.au/news/, accessed 25 January 2010. 15 Markus, Andrew and Dharmalingham, Arunachalam (2007). Attitudinal divergence in a Melbourne region of high immigrant concentration: A case study', People and Place, vol. 15, 4: 38-48. 
are considered in the context of two recent surveys which provide variables for analysis: the 2007 national social cohesion survey and the 2007 Community Indicators Victoria survey ${ }^{16}$.

Divergence in attitude across ethnic groups is first considered. This issue is explored by comparing those whose first language is English with those whose first language is other than English (termed ESB and NSEB in the following discussion), and with regard to two questions.

First, responses are considered to the general proposition that immigrants from many countries make Australia stronger' (Table 1). This is the sort of question that yields a high level of agreement: some $66 \%$ per cent of ESB and 75 per cent of NESB; difference is more marked when level of 'strong agreement' (20 per cent, 34 per cent) and disagreement ( 28 per cent, 15 per cent) is considered, with differentiation in the range 10-15 percentage points.

Table 1 Accepting immigrants from many different countries makes Australia stronger. Response cross-tabulated by first language.

\begin{tabular}{lrc}
\hline & English & Other than English \\
\hline Strongly agree & $19.7 \%$ & $34.4 \%$ \\
Agree & $45.9 \%$ & $40.5 \%$ \\
(Neither agree or disagree) & $3.5 \%$ & $2.4 \%$ \\
Disagree & $19.1 \%$ & $11.9 \%$ \\
Strongly disagree & $8.6 \%$ & $3.4 \%$ \\
(None of the above/ Don't know) & $2.9 \%$ & $7.5 \%$ \\
(Refused) & $0.2 \%$ & $0.0 \%$ \\
Total & $100.0 \%$ & $100.0 \%$ \\
$\mathrm{~N}$ & 1695 & 294 \\
\hline
\end{tabular}

Source: Scanlon Foundation social cohesion survey - national (2007)

The issue of government assistance to ethnic minorities for maintenance of customs and traditions (identified in the previous discussion as a question that receives endorsement only from a minority) yields more marked differentiation - at the level of 30-40 percentage points. (Table 2). Thus the relative level of 'strong agreement' for the ESB/ NESB groups is 6 per cent/24 per cent, the level of aggregated agreement is 26 per cent/64 per cent. The level of aggregated disagreement is of similar (but inverse) proportion, 68 per cent/29 per cent. Thus opinion on what has been termed 'hard' multiculturalism sees sharply divided opinion, as Betts argued, between the ESB and NESB groups.

16 Markus, Andrew and Dharmalingham, Arunachalam (2008). Mapping Social Cohesion, Institute for the Study of Global Movements, Monash University, http://www.globalmovements.monash.edu.au/, accessed 8 April 2009; Community Indicators Victoria (2007). SPSS data file, The McCaughey Centre, VicHealth Centre for the Promotion of Mental Health and Community Wellbeing, University of Melbourne. 
Multiculturalism and Integration

Table 2 Ethnic minorities in Australia should be given Australian government assistance to maintain their customs and traditions. Response cross-tabulated by first language.

\begin{tabular}{lrc}
\hline & English & Other than English \\
\hline Strongly agree & $6.4 \%$ & $24.1 \%$ \\
Agree & $20.0 \%$ & $40.0 \%$ \\
(Neither agree or disagree) & $3.4 \%$ & $1.7 \%$ \\
Disagree & $39.1 \%$ & $16.6 \%$ \\
Strongly disagree & $28.7 \%$ & $12.2 \%$ \\
(None of the above/ Don't know) & $2.2 \%$ & $5.4 \%$ \\
(Refused) & $0.2 \%$ & $0.0 \%$ \\
Total & $100.0 \%$ & $100.0 \%$ \\
$\mathrm{~N}$ & 1692 & 295 \\
\hline
\end{tabular}

Source: Scanlon Foundation social cohesion survey - national (2007)

Analysis of the 2007 Community Indicators Victoria, with its large respondent base, enables closer analysis of the majority group, those whose 'main language spoken at home' is English, constituting over 23,000 respondents. Four key variables - gender, age, education and income - are considered in response to the general proposition that 'it is a good thing for a society to be made up of people from different cultures' (Table 3). As noted, this question elicited a very high level of aggregated agreement, at 88 per cent of respondents. In the following analysis attention is directed to those indicating the strongest level of agreement (on a five point scale), as this level provides evidence of substantial variation and thus provides clearer insight into the basis of variation.

This analysis yields the following conclusions: there is minimal variation by gender; analysis by age group yields more variation, at 20 percentage points amongst those in 'strong agreement', with three demarcations, those aged 18-44, 45-64, and 65 and above; consideration of gross household income indicates that level of 'strong agreement' increases with income; and, the sharpest differentiation is yielded by level of education, with strong agreement ranging from 33 per cent amongst those with some high school education to 63 per cent of those with some tertiary education. 
Table 3 'Strongly agree' and combined 'Strongly agree and Agree' that 'it is a good thing for a society to be made up of people from different cultures. Cross-tabulations for respondents who indicated English as the main language spoken at home.

\begin{tabular}{|c|c|c|c|c|c|c|c|}
\hline Gender & Male & Female & & & & & \\
\hline $\begin{array}{l}\text { Strongly } \\
\text { agree } \\
\text { Total agree }\end{array}$ & $\begin{array}{l}48.5 \% \\
86.1 \%\end{array}$ & $\begin{array}{l}48.9 \% \\
89.7 \%\end{array}$ & & & & & \\
\hline Age & $18-24$ & $25-34$ & $35-44$ & $45-54$ & $55-64$ & $65-74$ & 75 plus \\
\hline $\begin{array}{l}\text { Strongly } \\
\text { agree } \\
\text { Total agree }\end{array}$ & $\begin{array}{l}57.9 \% \\
91.7 \%\end{array}$ & $\begin{array}{l}59.5 \% \\
92.5 \%\end{array}$ & $\begin{array}{l}55.8 \% \\
91.1 \%\end{array}$ & $\begin{array}{l}46.4 \% \\
86.9 \%\end{array}$ & $\begin{array}{l}42.0 \% \\
85.1 \%\end{array}$ & $\begin{array}{l}33.9 \% \\
81.8 \%\end{array}$ & $\begin{array}{l}29.0 \% \\
81.9 \%\end{array}$ \\
\hline $\begin{array}{l}\text { Gross } \\
\text { household } \\
\text { income }\end{array}$ & $\begin{array}{r}\$ 0- \\
\$ 20 k\end{array}$ & $\begin{array}{l}\$ 20- \\
\$ 40 k\end{array}$ & $\begin{array}{l}\$ 40- \\
\$ 60 k\end{array}$ & $\begin{array}{l}\$ 60- \\
\$ 80 k\end{array}$ & $\begin{array}{l}\$ 80 k- \\
\$ 100 k\end{array}$ & $\begin{array}{l}\$ 100 k- \\
\$ 120 k\end{array}$ & $+\$ 120 k$ \\
\hline $\begin{array}{l}\text { Strongly } \\
\text { agree } \\
\text { Total agree }\end{array}$ & $\begin{array}{l}37.2 \% \\
82.8 \%\end{array}$ & $\begin{array}{l}40.8 \% \\
85.7 \%\end{array}$ & $\begin{array}{l}47.9 \% \\
88.1 \%\end{array}$ & $\begin{array}{l}52.8 \% \\
90.0 \%\end{array}$ & $\begin{array}{l}54.4 \% \\
89.9 \%\end{array}$ & $\begin{array}{l}59.1 \% \\
92.2 \%\end{array}$ & $\begin{array}{l}62.7 \% \\
92.9 \%\end{array}$ \\
\hline $\begin{array}{l}\text { Highest } \\
\text { level } \\
\text { education }\end{array}$ & $\begin{array}{r}\text { Completed } \\
\text { Primary }\end{array}$ & $\begin{array}{r}\text { Some } \\
\text { high } \\
\text { school }\end{array}$ & $\begin{array}{r}\text { Completed } \\
\text { high } \\
\text { school }\end{array}$ & $\begin{array}{r}\text { Trade } \\
\text { certificate } \\
\text { Diploma }\end{array}$ & $\begin{array}{r}\text { Some } \\
\text { tertiary }\end{array}$ & & \\
\hline $\begin{array}{l}\text { Strongly } \\
\text { agree } \\
\text { Total agree }\end{array}$ & $\begin{array}{l}18.3 \% \\
81.8 \%\end{array}$ & $\begin{array}{l}32.5 \% \\
81.5 \%\end{array}$ & $\begin{array}{l}50.2 \% \\
88.9 \%\end{array}$ & $\begin{array}{l}45.6 \% \\
87.5 \%\end{array}$ & $\begin{array}{l}63.1 \% \\
93.0 \%\end{array}$ & & \\
\hline
\end{tabular}

Source: Community Indicators Victoria (2007)

This data also provides indication of direction of change over time. With the increasing levels of university level education across Australian society there is expectation of higher levels of support for the various aspects of multicultural policy. Indicative of the pace of change, over the ten years 1996-2006 Victorian residents with a university degree increased by nearly 75 per cent, or from 392,656 to 678,392 . In 200619 per cent of the Victorian population aged 15 and above had a university degree ${ }^{17}$.

\section{Patterns of response}

In addition to the work of Betts already noted, a number of researchers have considered attitudes towards settlement policy. Professor Ien Ang, one of the authors of the 2002 SBS sponsored study Living Diversity, concluded that '... there is a high degree of ambivalence about cultural diversity in Australia' ${ }^{18}$. A leading Melbourne pollster, Irving Saulwick, has commented on the strong

17 Australian Bureau of Statistics (2007). 2006 Census Community Profile Series. Victoria. Time series profile, cat: 2003.0, Commonwealth of Australia.

18 Ang, Ien, Brand, Jeffrey E, Noble, Greg and Wilding, Derek (2002). Living Diversity. Australia's multicultural future, Special Broadcasting Service Artarmon, http://www20.sbs.com.au/sbscorporate/index. php?id=547, accessed 8 April 2009: 22. 
desire for unity in Australia. His findings indicated that the concept of multiculturalism raised in many minds an emphasis on separateness rather than togetherness $^{\prime 19}$.

In 1999 Professor Murray Goot drew attention to the contradictory character of public opinion:

On the question of assimilation versus multiculturalism, the surveys suggest that the public subscribes to both. It appears to recognise the inevitability, even the advantages, of a society which in many respects is culturally diverse while at the same time wanting migrants in other respects to be 'one of us' ${ }^{20}$.

More recently, in a 2005 article, Goot and Ian Watson concluded that 'Depending on how it is presented to survey respondents, statements about multiculturalism can be widely accepted, widely opposed, or can divide opinion down the middle' ${ }^{21}$.

This judgement, with its depiction of variation to all points of the compass, is open to the criticism that it is too sweeping. Rather, there is a largely consistent pattern of response - types of question yield predictable types of response. This is further illustrated by the findings of the 2002 Living Diversity study: broad questions, for example the question of general benefit to Australia of immigration, yield positive responses at the level of 80 per cent; statements about the enjoyment of eating food from other cultures are endorsed by 72 per cent; more specific statements, for example, concerning the benefit of cultural diversity, finds majority support, but at 59 per cent; a general statement concerning the encouragement to migrants to retain cultural identity splits opinion, with 52 per cent in favour and 48 per cent undecided or against. And as has been shown, when the prospect of government funding is introduced, there is majority opposition. The underlying reality, as noted by Irving Saulwick, is the strong desire for unity. Survey findings indicate that unity is understood in terms of a common culture.

In addition to these generalisations concerning the nature of response to a range of general and specific propositions, variance within the population needs to be recognised. The marked division between those of English-speaking and non-English speaking background, highlighted by Betts and others, is a key social variable. Within specific ethnic groups, level of education provides a key indicator of openness to other cultures and support for cultural maintenance.

19 Saulwick in National Multicultural Advisory Council (1999), Australian Multiculturalism for a New Century, http://www.immi.gov.au/media/publications/multicultural/nmac/report.pdf, accessed 25 January 2010: 91, 96.

20 Goot, Murray (1999). Op cit: 31.

21 Goot, Murray, and Watson, Ian (2005). 'Immigration, multiculturalism and national identity', in S Wilson, G Meagher, R Gibson, D Denemark and M Western (eds), Australian Social Attitudes. The first report, UNSW Press, Sydney: 185. 